\title{
Yöneticiye Güven ve Dağıtımsal Adalet Çalışanların İşe Gömülmüşlüğünü Nasıl Etkiler?
}

\author{
How the Manager Trust and Distributive Justice Can Affect the Employees' Job \\ Embeddedness
}

Yılmaz AKGÜNDÜZ1 ${ }^{1}$, Tülay GÜZEL ${ }^{2}$, Serhat HARMAN

\begin{abstract}
ÖZET
Bu çalışmanın amacı yöneticiye güven ve dağıtımsal adaletin çalışanların işe gömülmüşlükleri üzerindeki etkisini belirlemektir. Bu kapsamda öncelikle İşe Gömülmüşlük Ölçeğinin Türkçeye uyarlaması yapıldıktan sonra; işe gömülmüşlük, yöneticiye güvenvedağıtımsaladaletölçekleriniiçerenbiranket formu hazırlanmıştır. Çalışmanın temel bulguları (1) Türkçeye çevrilen Global İşe Gömülmüşlük Ölçeğinin geçerli ve güvenilir olduğunu, (2) hem yöneticiye güvenin hem de dağıtımsal adaletin çalışanların işe gömülmüşlüklerini etkilediğini, buna karşın yöneticiye güvenin çalışanların işe gömülmüşlüğünü dağıtımsal adalete göre daha fazla etkilediğini göstermektedir.
\end{abstract}

Anahtar Kelimeler: İşe gömülmüşlük, yöneticiye güven, dağıtımsal adalet, otel işletmeleri.

\section{Giriş}

Otel işletmelerinin yapısal özellikleri nedeniyle (düşük ücret, uzun çalışma saatleri, mevsimsellik, ağır iş yükü vb.) işgören devir hızı oldukça yüksektir. İşgören devri işletmenin katlanması gereken binlerce dolara yaklaşan maliyetleri de beraberinde getirdiği için işgören devir hızının yüksek olması otel işletmelerinin en önemli problemlerden birisi olarak kabul edilmektedir (Ghiselli vd, 2001; Tracey ve Hinkin, 2008). Otel işletmelerinin rekabet avantajı kazanabilmelerinde ve bu avantajı sürdürebilmelerinde, kalifiye işgücünü örgüte çekmek kadar örgütte kalmasını sağlamak da önemlidir. Bu kapsamda çalışanların işe gömülmüşlüklerini artırmak aynı zamanda çalışanların işten ayrılma niyetlerinin azalmasını sağlayabilecektir.

\begin{abstract}
The aim of this study is to reveal the effect of manager trust and distributive justice on employees' job embeddedness. In this scope, Global Job Embeddedness Scale was adapted to Turkish language at first and then a questionnaire composing the scale of job embeddedness, manager trust and distributive justice was prepared. Major findings from the empirical study are (1) adapted version of Global Job Embeddedness Scale to Turkish language is reliable and valid, (2) although both manager trust and distributive justice have an effect on the employees' job embeddedness, it is understood, in the model that manager trust significantly outweigh the distributive justice with regard to influence on employees' job embeddedness.
\end{abstract}

Keywords: Job embeddedness, manager trust, distributive justice, hotels.

İse gömülmüşlük çalışanların kişisel özelliklerinden etkilendiği gibi sektördeki iş fırsatlarından ve örgüt içi uygulamalardan da etkilenebilmektedir. Çalışanların örgütteki davranışlarının ortaya çıkmasında güven ve adalet algıları önemli bir yer tutmaktadır.

Sosyal Değişim Kuramına göre, çalışanlar örgüt içerisinde desteklendiklerine inandıklarında, yöneticilerine güvendiklerinde ve kaynakların adil olarak dağıtıldığını düşündüklerinde çalışanların işten ayrılma niyetlerinin azalması beklenmektedir. İşe gömülmüşlük, işgörenlerin işte kalma kararını olumlu olarak etkileyen önemli bir değişken olarak kabul edilmektedir (Holtom vd., 2006). Bu çalışmanın amacı orjinali İngilizce olan Global İşe Gömülmüşlük Ölçeğini Türkçeye uyarlamak; yöneticiye güven ve 
dağıtımsal adaletin çalışanların işe gömülmüşlükleri üzerindeki etkisini belirlemektir. Bu kapsamda işe gömülmüşlük, yöneticiye güven ve dağıtımsal adalet ile ilgili kuramsal açıklamalarda bulunulduktan sonra hipotezler açıklanmıştır. Çalışmada daha sonra otel işletmelerinde yapılan alan araştırmasına ait yöntem ve bulgulara yer verilmiştir. Son bölümde bulgular alanyazındaki bulgular ile karşılaştırılarak, otel yöneticilerine yönelik öneriler getirilmiş ve araştırmanın sınırlılıkları ile çalışma tamamlanmıştır.

\section{2. İşe Gömülmüşlük, Dağıtımsal Adalet ve Yöneticiye Güven Kavramlarına Yönelik Literatür Taraması}

\section{1. İşe Gömülmüşlük}

Iş tatmini, iş bağlıığı ve örgütsel bağlılık gibi işe gömülmüşlük de çalışanların örgütte kalma isteklerini artıran faktörlerden birisi olarak kabul edilmektedir (Jang ve George, 2012; Robinson vd., 2014; Yang, 2010; Zopiatis vd., 2014). İşe gömülmüşlük çalışanın işe ve örgüte yerleşme derecesini gösteren bir yapıdır (Sekiguchi vd., 2008). Bu yapı, örgütsel ve toplumsal gömülmüşlük olarak iki boyutta incelenir. Bu boyutların her biri kendi içerisinde uyum, ilişki ve fedakarlık olmak üzere üç alt boyuttan oluşmaktadır (Mitchell vd., 2001).

Uyum boyutu, çalışanların kendilerini çalıştıkları örgüt ve çevre ile uyumlu olarak algılamalarıdır. Çalışanların kişisel değerleri ve kariyer planları; iş bilgisi ve işi yapabilme becerisi; işin özellikleri çalışan ile örgüt arasındaki uyumun önemli unsurları olarak kabul edilmektedir (Holtom ve O'Neill, 2004). Ayrıca örgütün bulunduğu konum, politik ve sosyo-kültürel çevre, iklim şartları ve çevrenin sunduğu rekreatif etkinlikler çalışan ve toplum arasında uyumun sağlanabilmesinde etkili olan diğer unsurlardır (Mitchell vd., 2001). Çalışanın değerleri ile örgütün değerleri arasında bir uyumun olması çalışanların işe gömülmüşlüklerini artırırken; çalışanlar ve örgüt arasında uyumun düşük olması işgören devir hızını artırmaktadır (Cable ve Judge, 1996; Chatman, 1991).

İlişki boyutu, çalışanlar ile örgüt ve örgütün çevresi arasındaki hem formal hem de informal olarak ortaya çıkan ilişkiler ile karakterize edilir. Bu ilişkilerin sayısı ve şiddeti değişmesine rağmen; çalışanların örgüt ve örgütün çevresi ile daha fazla ilişkiye girmesi çalışanların işe gömülmüşlüklerini artırır. Çalışanların örgütün fiziksel çevresi, örgütteki arkadaşları, işle ilgili gruplar ve diğer gruplar ile kurduğu ilişkiler işe gömülmüşlüklerini artııır (Holtom ve O'Neill, 2004).

Fedakarlık boyutu ise çalışanın işten ayrılması durumunda, iş değiştirmesi nedeniyle ortaya çıkabilecek psikolojik ve maddi kayıpları ifade etmektedir (Holtom vd., 2006; Mitchell vd., 2001). Dahil olduğu yeni örgütün, ayrıldığı örgütün sağlayacağı emeklilik ve maaş gibi maddi yararları; iş güvencesi ve terfi olanakları gibi kolaylıkları sağlayamaması çalışanların katlanmaları gereken fedakarlıklar arasında yer almaktadır (Mitchell vd., 2001).

Turizm alanında işe gömülmüşlük ile ilgili oldukça sınırlı sayıda çalışma bulunmaktadır (Akgunduz ve Cin, 2015; Robbinson vd., 2014). En yeni çalışmadan başlanacak olunursa; Akgunduz ve Cin (2015) Ankara'daki otel işletmelerinde dağıtımsal adaletin çalışanların işten ayrılma niyetleri üzerindeki negatif etkisini, işe gömülmüşlüğün güçlendirdiğini; Robbinson et al. (2014) önbüro çalışanları üzerinde yaptığı çalışmada işe gömülmüşlüğün işten ayrılma niyetini olumsuz olarak etkilediğini; Karatepe ve Shahriari (2014) örgütsel adalet algısı ile işten ayrılma niyeti arasındaki ilişkide çalışanların işe gömülmüşlük davranışlarının işten ayrıma niyetini azalttığını; Karatepe ve Ngeche (2012) iş bağlılı̆ğ ile iş performansı arasında işe gömülmüşlük davranışlarının aracılık etkisine sahip olduğunu; Karatepe ve Karadas (2012) güçlendirme ve hizmet iyileştirme performansı arasında işe gömülmüşlüğün aracılık etkisine sahip olduğunu belirlemiştir. Ayrıca diğer alanlarda yapılan araştırmalarda işe gömülmüşlüğün gönüllü işten ayrılmayı azalttığı tespit edilmiştir (Bergiel vd., 2009; Tanova ve Holtom, 2008).

\subsection{Yöneticiye Güven}

McAllister (1995)'a göre güven, bir kişinin başka bir kişinin sözlerinden, davranışlarından ve kararlarından emin olması ve bunlara göre hareket etme istekliliğidir. Güven, ilişkilerin uzun dönemli sürdürülebilmesi için temel unsur olarak kabul edilmektedir (Diffie-Couch, 1984). Otel işletmelerinde işbirliğine odaklı bir örgüt kültürünün oluşturulabilmesi için çalışanların hem yöneticilerine hem de çalışma arkadaşlarına güvenmeleri gerekir. Farklı yaşam tecrübesine sahip çalışanları, bir arada tutabilmek ve örgütsel amaçlar doğrultusunda hareket etmelerini sağlamak için güven esastır (Mayer vd., 1995). Ayrıca güvenin örgütlerde tutum, algı, davranış ve performans 
çıktıları üzerinde de belirleyici bir etkisi vardır (Dirks ve Ferrin, 2001).

Çalışanların yöneticilerine güvenlerini yöneticinin ulaşılabilir olması, becerisi, tutarlılığı, dikkatliliği, dürüstlüğü, doğruluğu, sadakati, açıklığı, sözünü tutması, yeni görüşlere açık olması ve genel olarak güvenilir olması etkilemektedir (Deluga, 1994). McAllister (1995) bireylerarası güveni bilişsel ve etki temelli güven olarak iki boyutta incelemiştir. Bilişsel güven diğer tarafın yükümlülüklerini yerine getirme yeteneğinin değerlendirilmesidir (Hopkins ve Weathington, 2006). Etki temelli güvende bireylerarası duygusal bağların oluşumu önemlidir. Etki temelli güven iki taraf arasında karşılıklı ilgi ve özenle gelişir (Hopkins ve Weathington, 2006). Bireylerarası güven ilişkilerini doğrulamak için hem bilişsel hem de etki temelli güvenin birlikte incelenmesini gerekmektedir (Webber ve Klimoski, 2004).

Çalışanların örgütsel güven algılarında temel belirleyici, yöneticilerine duydukları güvendir. Yöneticiye güven, çalışanların yöneticilerinin kendilerine sağladığı desteğe ilişkin algıları; yöneticilerinin doğru sözlü olacağına ve sözünün arkasında duracağınailişkin inançlarıveyöneticilerinin yeterliliklerine, adil davranacaklarına ve etik ilkelere bağlı kararlar alacaklarına yönelik inançları ile ilgilidir (Deluga, 1994; Mishra ve Morrisey, 1990). Örgütlerde çalışanların yöneticilerine güvenlerinin yüksek olması durumunda iş tatminleri, iş performansları, örgütsel bağlııkları, kararlara katılımları artarken; stres ve tükenmişlik düzeyleri, devamsızlık ve gönüllü işten ayrılma niyetleri azalmaktadır (Cunningham ve MacGregor, 2000; Folger ve Konovsky, 1989; Gregory vd., 2007; Hopkins ve Weathington, 2006; Kidd ve Smewing, 2001; Mayer ve Gavin, 2005; Martinussen vd., 2007; Renzl, 2008).

\subsection{Dağıtımsal Adalet}

Adams'ın Eşitlik Teorisi ile açıklanan dağıtımsal adalet, çalışanların görevler, fırsatlar, cezalar/ödüller, roller, statüler, terfiler ve ücretler gibi karşılaşılan sonuçların hakkaniyetli olarak dağıtılmasına ilişkin inançlarını kapsamaktadır (Colquitt, 2001). Dağıtımsal adaletin temeli Sosyal Değişim Teorisine dayanır (Blodgett, 1997).

Dağıtımsal adalet, çıktıların adil paylaşımı ile ilgilidir (Greenberg, 1990). Ahlaki ve nesnel olarak tanımlanan özellikler temelinde, benzer olan bireylere benzerlikleri ve farklı olan bireylere de farklılıkları oranında davranılması beklenir (Foley vd., 2002). Çalışanlar elde ettikleri kazanımların adil olup olmadığını belirlemek amacıyla örgüte ne verdiklerini ve örgütten ne aldıklarına bakarlar (Lambert, 2003). Örgüte katkıları ile örgütten sağladıkları ekonomik ve sosyo-psikolojik kazanımları arasında bir dengenin olduğunu algılamaları, çalışanlarda dağıtımsal adalet algısının oluşmasını sağlar (Cropanzano ve Ambrose, 2001).

Örgüt içi adalet algısı yüksek olan çalışanların iş tatmininin, örgütsel vatandaşlık davranışlarının ve performanslarının yüksek olması beklenmektedir (AlZu'bi, 2010; Jafari ve Bidarian, 2012; Zapata-Phealan vd., 2009). Ancak çalışanların katkı ve kazanımları arasında dengesizlik olması durumunda çalışanlarda güvensizlik ortaya çıkmaktadır (Wong vd., 2006). Buna bağlı olarak ise çatışmalar ve stres düzeyleri artarken; motivasyonu, iş tatmini, örgütsel bağlılık ve örgütsel vatandaşlık davranışları azalmaktadır (Cook ve Wall, 1980; Frone vd., 1992; Konovsky ve Pugh, 1994; Lambert vd., 2007;).

\section{HIPOTEZLERIN GELIŞTIRILIMESi}

Yöneticiler, çalışanların örgüte karşı tutumlarını ve örgüt içerisindeki davranışlarını belirleyen en önemli faktörlerden biri olarak kabul edilmektedir (Wang vd., 2005). Yöneticilerinin örgüt içerisindeki söylem ve davranışları arasında tutarlılık olduğuna, kararlarının adil olduğuna inanmaları çalışanların pozitif duygu ve davranışlarını artırmakta; negatif duygu ve davranışlarını ise azaltmaktadır (Konovsky ve Pugh, 1994; Lee vd., 2013; Mayer ve Gavin, 2005; Yoon ve Suh, 2003).

İşe gömülmüşlük, çalışanların işte/örgütte kalma kararlarını etkileyen faktörleri uyum, ilişki ve fedakarlık olarak üç faktör altında incelemektedir (Holtom vd., 2006). Çalışanların değerleri, kariyer amaçları ve gelecek planlarının işleri veya örgüt kültürleri ile uyumlu olması; örgütteki veya örgütün bulunduğu çevredeki diğer kişiler ile formal veya informal olarak aralarında iyi bir ilişki olması; örgütten ayrılması durumunda ortaya çıkacak maddi ve maddi olmayan fedakarlıkların kabul edilebilir sınırlarda olmaması çalışanların işten ayrılma niyetini olumsuz olarak etkilemektedir (Mitchell vd., 2001). Yöneticilerinin davranışlarının tutarlı olduğuna ve örgütsel çıktıların yöneticileri tarafından adil dağıtıldığına inanan çalışanlar işe ve örgüte daha fazla yerleşeceklerdir (Karatepe ve Shahriari, 2014). Bu nedenle, yöneticiye güvenin ve dağıtımsal adaletin, işe gömülmüşlük 
üzerinde pozitif etkisinin olması beklenmektedir. Yapılan açıklamalara bağlı olarak $\mathrm{H}_{1}$ ve $\mathrm{H}_{2}$ önerilmiştir:

$\mathrm{H}_{1}$ : Yöneticiye güven çalışanların işe gömülmüşlüklerini pozitif olarak etkiler.

$\mathrm{H}_{2}$. Dağıtımsal adalet çalışanların işe gömülmüşlüklerini pozitif olarak etkiler.

\section{YÖNTEM}

\subsection{Veri Toplama Aracı}

Araştırmada veriler, alan yazına dayalı olarak geliştirilen bir anket ile toplanmıştır. Ankette çalışanların işe gömülmüşlük belirlemek amacıyla Crossley ve diğerleri (2007) tarafından geliştirilen 7 maddeli Global İşe Gömülmüşlük Ölçeğinden; dağıtımsal adalet algılarını belirlemek amacıla Niehoff ve Moorman tarafından geliştirilen 5 maddeli Dağıtımsal Adalet Ölçeğinden; yöneticiye güvenlerini belirlemek amacıyla Lee ve diğerleri (2013) tarafından geliştirilen 5 maddeli Yöneticiye Güven Ölçeğinden yararlanılmıştır. Ölçeklerde yer alan maddeler Kesinlikle Katılmıyorum (1) ve Kesinlikle Katılıyorum (5) olarak likert derecelendirmesinde ifade edilmiştir.

\subsection{Evren ve Örneklem}

Araştırmanın evrenini İstanbul'da bulunan işletme belgeli konaklama işletmelerinin çalışanları oluşturmaktadır. Türkiye Otelciler Federasyonunu verilerine göre 2013 yılında 168.124 oda ve 359.912 yatak bulunmaktadır. Günümüz Türkiye koşullarında odabaşına ortalama 0,80 personel istihdam edildiğinden hareketle evren büyüklüğü 134.499 kişi olarak tahmin edilmiştir (Çakıcı ve Yılmaz, 2012). Örneklem büyüklüğü \%95 güven düzeyinde ve $\% 5$ örneklem hatası ile 384 kişi olarak hesaplanmıştır (Sekaran, 1992).

Araştırmada veriler 1 Ocak - 30 Mart 2014 döneminde toplanmıştır. Ankete cevap veren tüm çalışanlar örnekleme dahil edilmek istendiği için olasılığa dayalı olmayan örnekleme yöntemlerinden kolayda örnekleme yöntemi tercih edilmiştir. Ancak izin sorunları nedeniyle belirlenen örneklem büyüklüğüne ulaşılamamıştır. Anket uygulama dönemi sonunda geçerli 293 anket toplanabilmiştir. Veriler bilgisayar ortamına aktarıldıktan sonra tanımlayıcı istatistiklerin dışında güvenilirlik ve geçerlilik analizlerine bağlı olarak çalışmanın hipotezlerini test etmek için yapısal eşitlik modelinden yararlanılmıştır.

\section{BULGULAR}

Orjinali İngilizce olan Global İşe Gömülmüşlük Ölçeğine, Türkçe çevirisi yaptırılmış ve üç akademisyene kontrol ettirilerek sonra son hali verilmiştir. Daha sonra 7 maddeden oluşan ölçeğin geçerliliğini ve güvenirliğini belirlemek amacıyla pilot bir uygulama yapılmıştır. 30 kişinin katıldığı pilot uygulamada 7 madde tek bir boyutta toplanmıştır. Ölçeğe ilişkin açıklayıcı faktör analizine ilişkin madde faktör yükleri ve ortalamaları, açıklanan varyans ve öz değerleri Tablo 1'de yer almaktadır. Ayrıca Cronbach Alfa ve Split Half değeri de tabloda görülmektedir.

Tablo 1: İşe Gömülmüşlük Ölçeğinin Açıklayıcı Faktör Analizi

\begin{tabular}{|c|c|c|c|c|c|}
\hline Ifade & $\begin{array}{l}\text { Faktör } \\
\text { Yükü }\end{array}$ & Ortalama & $\begin{array}{l}\text { Açılanan } \\
\text { Varyans }\end{array}$ & Özdeğer & Güvenirlik \\
\hline Bu otelin bir parçası olduğumu hissediyorum. & ,775 & 4,1399 & 52,989 & 3,709 & ,850 \\
\hline Bu otelden ayrılmak, benim için oldukça zor. & 759 & 4,3584 & & & \\
\hline $\begin{array}{l}\text { Otelden ayrılamayacak kadar bu işe kendimi } \\
\text { kaptırmış durumdayım. }\end{array}$ & ,740 & 4,2355 & & & \\
\hline $\begin{array}{l}\text { Ayrılamayacak kadar kendimi bu otele bağlı } \\
\text { hissediyorum. }\end{array}$ & ,729 & 4,1741 & & & \\
\hline $\begin{array}{l}\text { Otelin bana sağladıklarını (ücret, ikramiye, } \\
\text { sosyal haklar vb.) düşündüğümde, bu otelden } \\
\text { ayrılmam çok kolay olmaz. }\end{array}$ & 723 & 4,1604 & & & \\
\hline $\begin{array}{l}\text { Çalışma arkadaşlarımla kurduğum ilişkiler } \\
\text { otelden ayrılmamı zorlaştırır. }\end{array}$ & ,694 & 4,1911 & & & \\
\hline Otelde olup-biteni yakından takip ederim. & ,670 & 4,2081 & & & \\
\hline
\end{tabular}


Açıklayıcı faktör analizi ile ortaya çıkan tek boyutlu yapı doğrulayıcı faktör analizi (DFA) ile de test edilmiştir. DFA'ya ilişkin t-değerleri ve standart çözümleme değerleri Şekil 1'de yer almaktadır. Yapılan DFA'nde t-değerlerinin 10,57 ile 13,53 arasında; standardize çözümleme değerlerinin 0,60 ile 0,73 arasında değiştiği; $X^{2}=36,75 \mathrm{df}=14$ olmasına bağlı olarak $X^{2} / d f=2,62$ Normed Fit Index $(N F I)=0,97$ Non-Normed Fit Index (NNFI) $=0,97$ Parsimony Normed Fit Index (PNFI)=0,65 Comparative Fit Index
$(C F I)=0,98$ Incremental Fit Index (IFI) $=0,98$ Relative Fit Index $(\mathrm{RFI})=0,96$ Root Mean Square Residual $(\mathrm{RMR})=0,037$ Standardized $\mathrm{RMR}=0,036$ Goodness of Fit Index $(\mathrm{GFI})=0,97$ Adjusted Goodness of Fit Index $(\mathrm{AGFI})=0,93$ Parsimony Goodness of Fit Index $(P G F I)=0,48$ olduğu belirlenmiştir. Söz konusu değerlere bağlı olarak 7 maddeden oluşan Global İşe Gömülmüşlük ölçeği bu hali ile geçerli ve güvenilir bir ölçme modeli olarak kabul edilmiştir.

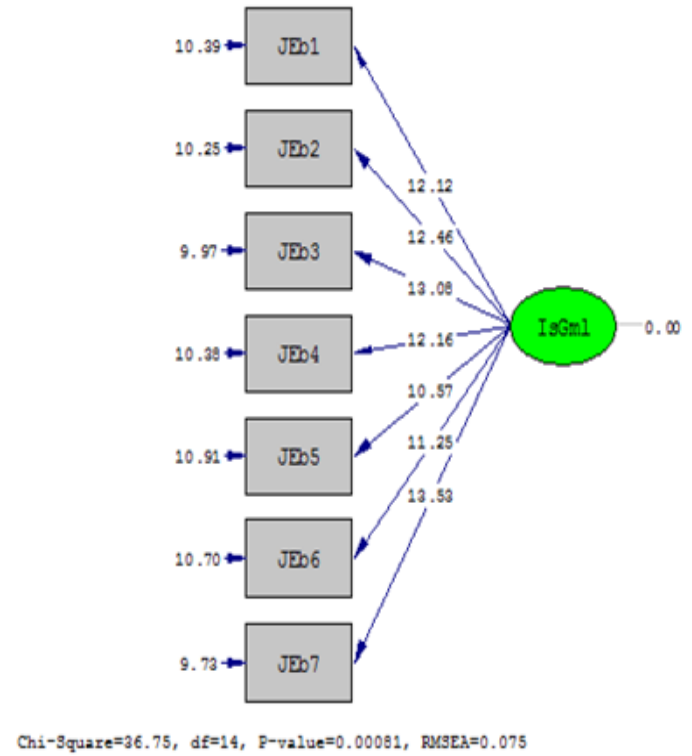

Şekil 1: Global İşe Gömülmüşlük Ölçeğine İlişkin DFA
Araştırma kapsamında önerilen hipotezleri test etmek için Anderson ve Gerbing (1988) tarafından önerilen iki aşamalı yaklaşımdan yararlanılmıştır. İlk aşamada ölçme modeline dahil edilen ölçeklerin ayırt edici ve yakınsak geçerliliklerini belirlemek amacıyla doğrulayıcı faktör analizi (DFA) yapılmıştır (Fornell ve Lacker, 1981). Modelde yer alan ölçeklerin güvenirlikleri Cronbach' Alpha ile belirlenmiştir. İkinci aşamada yapısal eşitlik modellemesi ile hipotezler test edilmiştir.

Araştırma kapsamında modele dahil edilen ölçeklerin geçerliliğini belirlemek amacıyla DFA yapılmıştır. İlk yapılan DFA'nde standardize yük değeri ve t-değeri kabul edilebilir sınırlar içerisinde olmayan İşe gömülmüşlük ve yöneticiye güven latent değişkenlerindeki bir, dağıtımsal adalet latent değişkenindeki iki gözlenen değişken analizden çıkartıldıktan sonra DFA tekrar edilmiştir. Söz konusu üç gözlenen değişken analizden çıkartıldıktan sonra ölçme modelinde yer alan hem gözlenen hem de latent değişkenlere ilişkin standardize çözümleme değerlerinin ve t-değerlerinin kabul edilebilir sınırlarda olduğu tespit edilmiştir.

Ölçme modelinde yer alan latent ve gözlenen değişkenlerin istatistiksel olarak anlamlı olarak kabul edilebilmesi için t-değerlerin1,96'ın üzerinde olması gerekmektedir (Hair, Black, Babin ve Anderson, 2010). Şekil 2'de yer alan işe gömülmüşlük, yöneticiye güven, dağıtımsal adalet latent değişkenlerin bulunduğu ölçme modelinde yer alan tüm yollara ait t-değerlerinin 8,99 ile 14,96 arasında değiştiği görülmektedir. 


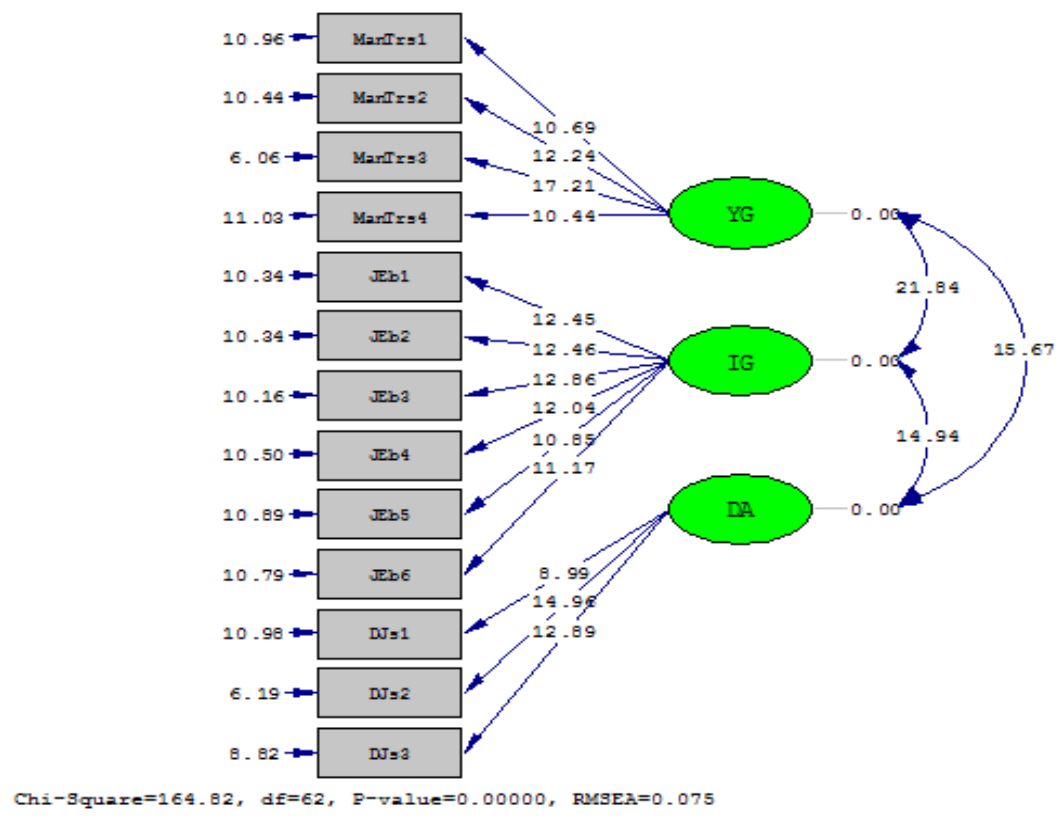

Şekil 2: Ölçme Modeline Illişkin DFA (t-değerleri)

Ayrıca ölçme modeline ait standardize çözümleme değerlerinin 0,50 altında olmaması ölçme modelinin kabul edilmesinde önemli bir göstergedir. Şekil 3'de yer alan ölçme modeline ait standardize çözümleme değerlerinin 0,54 ila 0,87 arasında değiştiği tespit edilmiştir. Ölçme modeline ait standardize değerlerin ve $\mathrm{t}$-değerlerin kabul edilebilir sınırlar içerisinde olması, modelin bir bütün olarak kabul edilmesinde gerekli olmakla birlikte tek başına yeterli değildir. Ayrıca uyum iyiliklerinin de istenilen sınırlarda olması gerekir. $X^{2} / d f^{\prime}$ nin 2 'nin altında olması iyi bir modeli 5 'in altında olması ise kabul edilebilir bir modeli işaret etmektedir (Hair ve diğerleri, 2010). Ölçme modelinde $X^{2}=164,82$ ve $\mathrm{df}=62$ olmasına bağlı olarak $X^{2} / \mathrm{df}=2,66$ RMSEA $=0,075 \quad \mathrm{NFI}=0,95 \quad \mathrm{NNFI}=0,96 \quad \mathrm{PNFI}=0,76$ $\mathrm{CF}=0,97 \mathrm{IFI}=0,97 \mathrm{RF}=0,94 \quad \mathrm{RMR}=0,055 \mathrm{RMR}=0,053$ $\mathrm{GFI}=0,92 \mathrm{AGFI}=0,88 \mathrm{PGF}=0,63$ olarak belirlenmiştir. Uyum iyilikleri değerlerinin de kabul edilebilir olması nedeniyle ölçme modelinin, kabul edilebilir bir model olduğunu söylemek mümkündür.

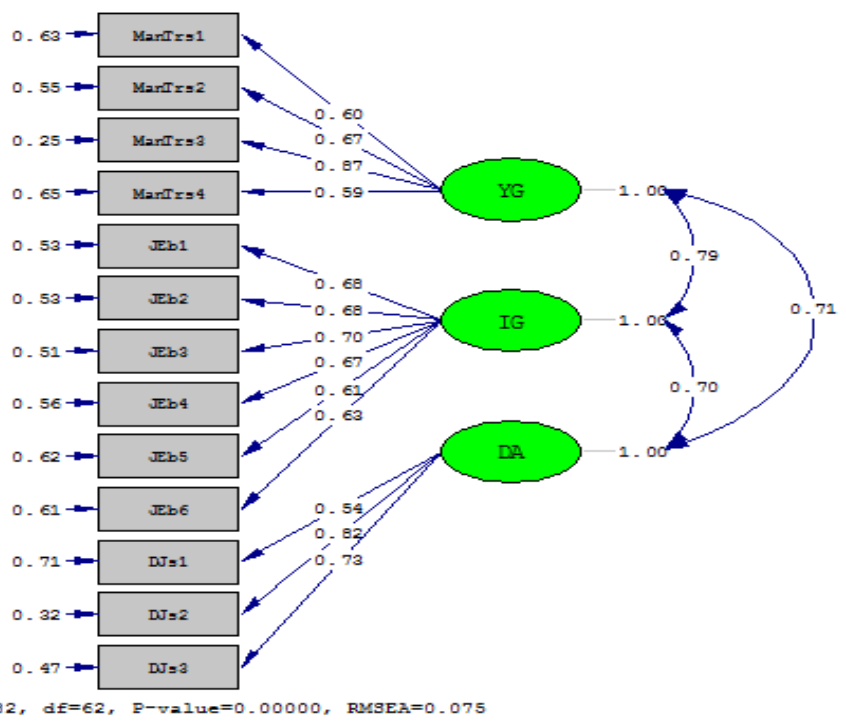

Şekil 3: Ölçme Modeline Ait DFA (Standardize Çözümleme Değerleri) 
Ölçme modelinin geçerliliği belirlendikten sonra değişkenlerin aralarındaki ilişki korelasyon analizi ile belirlenmiştir. Yöneticiye güven, dağıtımsal adalet ve işe gömülmüşlük değişkenlerinin güvenirlik, ortalama, standart hata ve korelasyon değerleri Tablo 3'de yer almaktadır.

Tablo 2: Değişkenlere Ait Ortalama, St. Hata, Güvenirlik ve Korelasyon Değerleri

\begin{tabular}{|l|c|c|c|c|c|}
\hline & Ortalama & St. Hata & $\mathbf{1}$ & $\mathbf{2}$ & $\mathbf{3}$ \\
\hline 1.Yöneticiye Güven & 4,010 &, 80 & $(, 792)$ & & \\
\hline 2.Dağıtımsal Adalet & 4,047 &, 81 &, $71^{* *}$ & $(, 717)$ &, $70^{* *}$ \\
\hline 3.Işe Gömülmüşlük & 4,221 &, 75 &, $79^{* *}$ & $(, 822)$ \\
\hline \multicolumn{7}{|l}{ Not: Parantez iç̧inde yer alan değerler Cronbach Alpha değerleridir. **p $<0,01(2$-yönlü) } \\
\hline
\end{tabular}

Tablo 3'de yer alan korelasyon tablosuna göre yöneticiye güvenin dağıtımsal adalet $(r=, 71 p<0,01)$ ve işe gömülmüşlük $(r=, 79 p<0,01)$ ile arasında; dağıtımsal adalet ile işe gömülmüşlük arasında $(r=, 70$ $p<0,01)$ anlamlı ve pozitif yönlü bir ilişkin vardır. Ayrıca değişkenlerin Cronbach' Alpha değerlerinin 0,70'in üzerinde olmasına bağlı olarak ölçeklerin içerik geçerliliğine sahip olduklarını söylemek mümkündür (Hair ve diğerleri, 2010).
Araştırma kapsamında önerilen hipotezleri test etmek için YEM'den yararlanılmıştır. Modelde işe gömülmüşlük bağımlı, yöneticiye güven ve dağıtımsal adalet bağımsız değişken olarak kabul edilmiştir. Şekil 5'de yer alan YEM'ne ait t değerlerinin 1,96'ın üzerinde olmasına bağlı olarak tüm yolların istatistiksel olarak anlamlı olduğunu söylemek mümkündür.

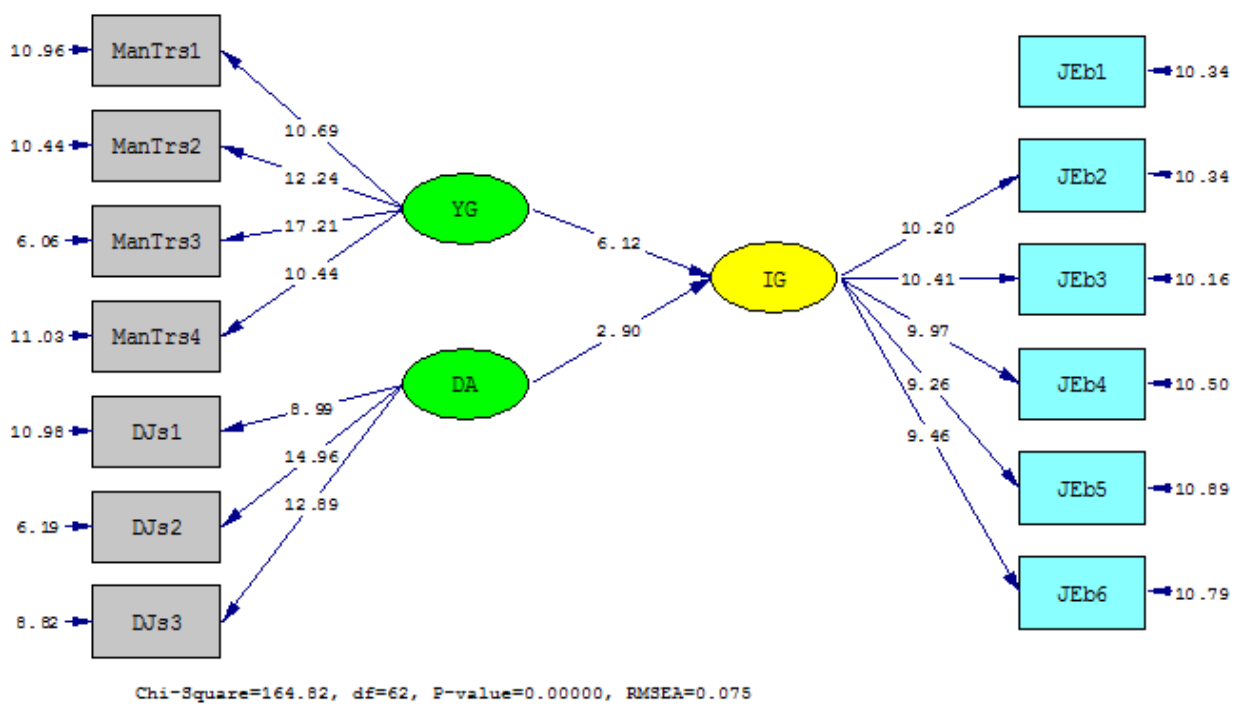

Şekil 5: YEM'ne ait t-değerleri

Bağımsız değişkenlerin bağımlı değişken üzerindeki etkisini gösteren ve bu etkinin yönünü gösteren YEM Şekil 6'da yer almaktadır. YEM'e göre yöneticiye güvenin işe gömülmüşlük üzerinde 0,60 ; dağıtımsal adaletin ise işe gömülmüşlük üzerinde 0,27 pozitif bir etkiye sahiptir. Ayrıca YEM'e ilişkin uyum iyilikleri $X^{2}=164,82 \mathrm{df}=62 \mathrm{X}^{2} / \mathrm{df}=2,66$
RMSEA $=0,075 \quad \mathrm{NFI}=0,95 \quad \mathrm{NNFI}=0,96 \quad \mathrm{PNFI}=0,76$ $C F I=0,97 \quad I F I=0,97$ RFI $=0,94$ RMR $=0,055$ SRMR $=0,053$ $\mathrm{GFI}=0,92 \mathrm{AGFI}=0,88 \mathrm{PGFI}=0,63$ olarak belirlenmiştir. $\mathrm{Bu}$ sonuçlar hem YEM'in bir model olarak kabul edilmesini sağlamakta hem de $\mathrm{H}_{1}$ ve $\mathrm{H}_{2}$ hipotezlerini desteklemektedir. 


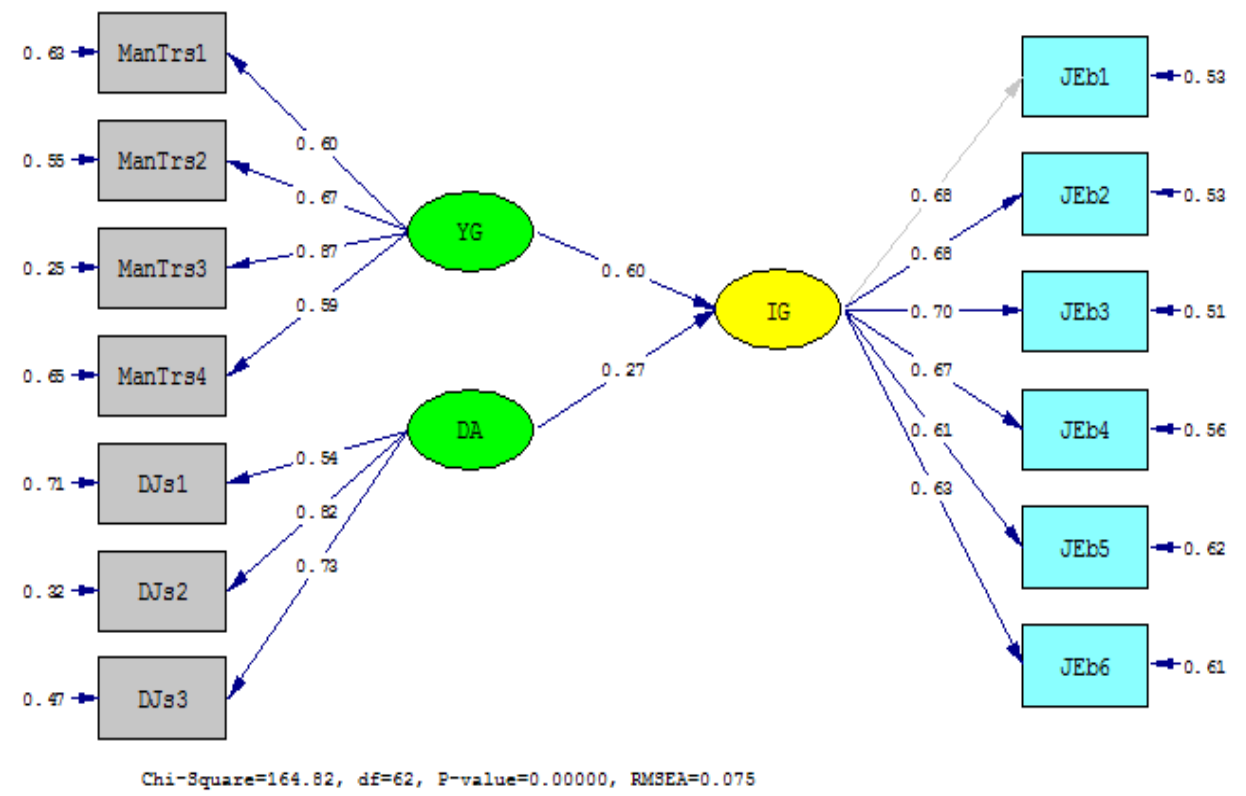

Şekil 6: YEM'e ait Standardize Değerler

\section{SONUÇ VE ÖNERILER}

Çalışmanın sonuç ve öneriler bölümü araştırma sonuçlarının alanyazında yer alan bulgular ile karşılaştırıldığı kuramsal çıktılar, otel işletmelerine ve yöneticilerine yönelik önerilerin yer aldığı uygulamaya yönelik çıktılar, çalışmanın sınırlılıkları ve gelecekte yapılacak çalışmalar için öneriler alt başlıklarından oluşmaktadır.

\section{Kuramsal Çıktılar}

Otel işletmeleri örnekleminde yapılan bu araştırmada dağıtımsal adaletin çalışanların işe gömülmüşlüklerini artırdığı belirlenmiştir. Akgunduz ve Cin (2015) tarafından Ankara'daki 5 yıldızlı otel çalışanları üzerinde yapılan çalışmada dağıtımsal adaletin işe gömülmüşlük ile anlamlı bir ilişkisinin olduğunu; dağıtımsal adaletin işe gömülmüşlük ile etkileşime girdiğinde dağıtımsal adaletin işten ayrılma niyeti üzerindeki negatif etkiyi güçlendirdiğini belirlemiştir. Ayrıca örgütsel adaletin bir alt boyutu olan dağıtımsal adalet ile ilgili yapılan araştırmalar, çalışanların dağıtımsal adalet algılarının yüksek olmasının örgüte karşı istendik tutum (örgütsel bağlılık, iş tatmini ve gönüllü işte kalma niyeti gibi) ve davranışlara (iş performansı gibi) sahip olmalarında etkili olduğunu göstermektedir (Akgündüz ve Şanlı, 2015; Crossley vd., 2007; Karatepe ve Shahriari, 2014; Karatepe ve Ngeche, 2012; Karatepe ve Karadas,
2012; Mitchell vd., 2001; Lee vd., 2004; Robbinson vd., 2014). Dağıtımsal adaletin otel işletmelerinde meydana getirdiği pozitif etki göz önüne alındığında İstanbul'daki otel çalışanların üzerinde yapılan bu çalışmanın daha önce yapılan çalışma bulguları ile benzerlik gösterdiğini söylemek mümkündür.

İstanbul'da yapılan bu araştırmanın diğer bir bulgusu yöneticiye güvenin çalışanların işe gömülmüşlüklerini artırdığıdır. Örgüt-çalışan, yönetici-ast, çalışan-çalışan ilişkisinde güven algısı ilişkileri güçlendirmekte ve çoğu zaman istendik sonuçlara neden olmaktadır. Yapılan araştırmalar örgütsel güven duygusu yüksek olan çalışanların örgütsel bağılıılarının, iş performanslarının, örgütsel destek algıları ve örgütsel vatandaşlık davranışlarının da yüksek olduğunu göstermektedir (Bolat ve Bolat, 2008; Halis vd. 2007, Randall, 1990, Şanlı, 2016). Dolayısıyla yöneticiye güvenin çalışanların işe gömülmüşlüklerini yükseltmesi de diğer pozitif sonuçlara etkisi ile tutarlılık göstermektedir.

\section{Uygulamaya Yönelik Çıktılar}

İstanbul'da yapılan bu alan araştırmasının sonuçlarına bağlı olarak otel çalışanlarının işe gömülmüşlüklerini artırmak için yöneticiye güvenlerinin ve dağıtımsal adalet algılarının yükseltilmesi gerektiğini söylemek mümkündür. Bu kapsamda yöneticiye güven, dağıtımsal adalet ve işe 
gömülmüşlüklerini artırmak için otel işletmelerine ve yöneticilerine şu önerilerde bulunulmuştur.

Çalışanların işe gömülmüşlüklerini artırmak için:

- $\quad$ Örgütün kariyer imkanları ile ilgili daha geniş bilgiler sağlanabilir,

- $\quad$ Kişisel değerleri örgütün değerleri ile uyumlu olan çalışanlar örgüte dahil edilebilir,

- Çalışanların hangi takım ya da projeye katılacağını seçimine izin verilebilir,

- Çalışanların bireysel ihtiyaçlarını (kafeterya gibi) giderecek hizmetler sağlanabilir,

- Kıdeme bağlı ikramiye ya da teşvik sağlanabilir,

- İşletmede çocuk bakımı hizmeti sunulabilir,

- Kar paylaşılabilir,

- Çalışanların örgüt kutlamalarını planlamalarına izin verilebilir,

- Tesislerin çevresindeki sosyal alanlar iyileştirilebilir,

- Çalışanların toplumsal aktivitelerden haberdar olmaları sağlanabilir,

- Yerel ulaşım desteği sağlanabilir,

- Boşalan kadrolara örgüt dışından transfer gerektirmeyen durumlarda çalışanlara terfi imkanı verilebilir,

- Çalışanlara işletmenin arabalarını kullanmalarına imkan verilebilir.

Çalışanların dağıtımsal adalet algılarını yükseltmek için:

- Performans değerlendirme süreci şeffaf hale getirilebilir,

- Çalışanlara performans değerlendirme süreci hakkında bilgi verilebilir,

- Performansa bağlı ikramiye, zam ve terfi gibi yapılabilir,

- Örgüt imkanlarından çalışanların eşit düzeyde yararlanması sağlanabilir,

- Yapılan terfi veya tenzili rütbenin gerekçesi örgüt içerisinde formal veya informal olarak çalışanlara aktarılabilir.

Çalışanların yöneticilerine güvenlerini artırmak için:

- Çalışanların hangi üste bağlı oldukları konusunda tereddütleri varsa giderilebilir,

- Çalışanların yöneticilerini tanımaları için sosyal ortamlarda imkanlar sunulabilir,
- Yönetici olarak görevlendirilecek kişiler işin gereklerine sahip ve etik değerlere bağlı kişilerden seçilebilir,

- Çalışanlarla ilgili kararların alınması sürecine, ilgili çalışanların da katılmaları sağlanabilir,

- Çalışanların ücret, ikramiye ve sosyal olanaklardan yararlanmalarında önemli farklılıklar olduğunda örgüt içerisinde bu farklılığın mantıklı gerekçeleri açıklanabilmeli,

- Yöneticilerin sözlerinin tutarlı ve gerçekçi olması sağlanabilir,

- Klasik olarak yapılan yöneticilerin astlarını değerlendirmelerinin dışına çıkılarak astların yöneticilerini değerlendirmelerine imkan sağlanabilir.

Çalışmanın Sınırlılıkları ve Yapılacak Çalışmalar İçin Öneriler

Bu çalışma İstanbul'da faaliyet gösteren işletme belgeli otel çalışanlarının işe gömülmüşlük, yöneticiye güven ve dağıtımsal adaleti değerlendirmeleri ile sınırlıdır. Gerekli örneklem büyüklüğüne ulaşılmamakla birlikte, tercih edilen veri toplama ve örnekleme yöntemi bu çalışmanın sınırlılıkları arasında kabul edilebilir. Bundan sonra yapılacak çalışmalarda otel departmanlara göre personel dağılımlarını dikkate alan kota örnekleme yönteminin kullanılması; anket sonuçlarının ayrıca derinlemesine mülakatlarla desteklenmesi; daha büyük bir örneklemde ve diğer turizm işletmelerinde de benzer çalışmaların yapılması, turizm sektörü işletmeleri açısından işe gömülmüşlük, yöneticiye güven ve dağıtımsal adalet konularının karşılaştırmalı olarak irdelenmesi olanağını verebilir. Böylece, turizm işletmelerinin sınıflamaları temelinde uygulamaya yönelik önerilerin geliştirilmesi olanağı elde edilebilir.

Bu çalışma işe gömülmüşlük, yöneticiye güven ve dağıtımsal adalet değişkenleri kapsamında gerçekleştirilmiştir. Sonraki çalışmalarda bu değişkenler ile birlikte işten ayrılma niyeti, kişilik özellikleri, örgütsel özdeşleşme, örgütsel sessizliğe ilişkin ifadelere yer verilmesi, daha farklı hipotezlerin sınanmasına ve yeni çıkarımlarda bulunulmasına yardımcı olabilecektir. Böylece, öznesinin ve nesnesinin insan olduğu hizmetin insan ile anlamlı hale geldiği otel işletmeciliği alanında, çalışanların işe gömülmüşlüklerine ilişkin çıkarımlar elde edilerek, yönetsel düzeyde örgütsel amaçları göz ardı etmeyen, pratiğe dönük ve çalışan odaklı kararların alınabilmesine katkı sağlanmış olur. 


\section{KAYNAKÇA}

Akgunduz, Y. ve Cin, F.M. (2015) "Job Embeddedness as a Moderator of the Effect of Manager Trust and Distributive Justice on Turnover Intentions" Anatolia, 26:(4): 549-562.

Akgündüz, Y. ve Şanlı, S.C. (2015) "İş Tatminin İşten Ayrılma Niyeti Üzerindeki Etkisinde İşe Gömülmüşlüğün Moderatör Etkisi" Çanakkale Onsekiz Mart Üniversitesi 16. Ulusal Turizm Kongresi Bildiri Kitabı: 438-453.

Al-Zu'bi, H., (2010) "A Study of Relationship between Organizational Justice and Job Satisfaction" International Journal of Business and Management, 5(12): 102-109.

Anderson, J. C. ve Gerbing, D. W. (1988) "Structural Equation Modeling in Practice: A Review and Recommended Two-Step Approach"Psychological bulletin, 103(3): 411.

Bergiel, E.B., Nguyen, V.Q., Clenney, B.F. ve Taylor, G.S. (2009) "Human Resource Practices, Job Embeddedness and Intention to Quit" Management Research News, 32(3): 205-219.

Blodgett, J.C., Hill, D.J. ve Tax, S.S. (1997) "The Effects of Distributive Procedural and Interactional Justice on Post complaint Behavior" Journal of Retailing, 73(2): 185-210.

Cable, D.M. ve Judge, T.A. (1996)"Person-Organization Fit, Job Choice Decision And Organizational Entry" Organizational Behavior and Human Decision Processes, 67, 294-311.

Chatman, J.A. (1991) "Matching People and Organizations: Selection and Socialization in Public Accounting Firms" Academy of Management Review, 36, 459-484.

Colquitt, J.A. (2001) "On The Dimensionality Of Organizational Justice: A Construct Validation of $A$ Measure" Journal of Applied Psychology, 86, 386-400.

Cook, J. ve Wall, T.D. (1980) "New Work Attitude Measures Of Trust, Organizational Commitment And Personal Need Non-Fulfillment" Journal of Occupational Psychology, 53, 39-52.

Cropanzano, R. ve Ambrose, M.L. (2001) "Procedural and Distributive Justice Are More Similar than You Think: A Monistic Perspective and A Research Agenda". Greenberg, J., Cropanzano, R. (eds.), Advances in Organizational Justice, California, Stanford University Press

Crossley, C.D., Bennett, R.J., Jex, S.M. ve Burnfield, J.L. (2007) “Development of a Global Measure Of Job
Embeddedness And Integration Into A Traditional Model Of Voluntary Turnover" Journal of Applied Psychology, 92(4): 1031-1042.

Cunningham, J.B. ve Gregor, J.M. (2000) "Trust and The Design of Work Complementary Constructs in Satisfaction and Performance" Human Relations, 53, 1575-1591.

Çakıcı, A. C. ve Yılmaz, B.E. (2012) “Mersin'deki Otel Çalışanlarının Nükleer Kaygıları, Çevresel Yaklaşım ve Çevreci Tüketim Eğilimleri Üzerine Bir Araştırma" Çağ Üniversitesi Sosyal Bilimler Dergisi, 9(2): 1-22.

Deluga, R.J. (1994) "Supervisor Trust Building, LeaderMember Exchange and Organizational Citizenship Behaviors" Journal of Occupational and Organizational Psychology, 67, 315-326.

Diffie-Couch, P. (1984) “Building A Feeling Of Trust In The Company" Supervisory Management, 29, 31-36.

Dirks, K. ve Ferrin, D. (2001) "The Role of Trust in Organizational Settings" Organization Science, 12(4): 450-467.

Foley, S., Kidder, D.L. ve Powell, G.N. (2002) "The Perceived Glass Ceiling and Justice Perceptions: An Investigation of Hispanic Law Associates" Journal of Management, 28(4): 471-496.

Folger, R. ve Konovsky M.A. (1989) "Effects of Procedural and Distributive Justice on Reactions to Pay Raise Decisions" Academy of Management Journal, 32, 115-130.

Fornell, C. ve Larcker, D.F. (1981)“Evaluating Structural Equation Models with Unobservable Variables and Measurement Error"Journal of Marketing Research, 18(1): 39-50.

Frone, M., Russell, M. ve Cooper, M. (1992) "Antecedents and Outcomes of Work-Family Conflict: Testing a Model of The Work Family Interface" Journal of Applied Psychology, 77, 65-75.

Ghiselli, R.F., Lalopa, J.M. ve Bai, B. (2001) "Job Satisfaction, Life Satisfaction and Turnover Intent among Food-Service Managers" Cornell Hotel \& Restaurant Administration Quarterly, 42, 28-37.

Greenberg, J. (1990)“Organizational Justice:Yesterday, Today, and Tomorrow" Journal of Management, 16, 399-432.

Gregory, D.M., Way, C.Y., LeFort, S., Barrett, B.J. ve Parfrey, P.S. (2007) "Predictors of Registered Nurses' Organizational Commitment and Intent to Stay" Management Review, 32, 119-127. 
Hair, J.F. Jr., Black, W.C., Babin, B.J. ve Anderson, R.E. (2010) Multivariate Data Analysis, 7th Edition, NJ, Prentice Hall.

Holtom, B.C., Mitchell T.R. ve Lee T.W. (2006) "Increasing Human and Social Capital by Applying Job Embeddedness Theory" Organizational Dynamics, 35(4): 316-331.

Holtom, B.C. ve O'Neill, B.S. (2004)“Job embeddedness: A Theoretical Foundation for Developing a Comprehensive Nurse Retention Plan" Journal of Nursing Administration, 34, 216-227.

Hopkins, S.M. ve Weathington, B.L. (2006) "The Relationships Between Justice Perceptions, Trust and Employee Attitudes in A Downsized Organization" The Journal of Psychology, 140(5): 447-498.

Jafari, P. ve Bidarian, S. (2012) The Relationship between Organizational Justice and Organizational Citizenship Behavior" Social and Behavioral Sciences, $47,1815-1820$.

Jang, J. ve George, T. (2012) "Understanding the Influence of Polychronicity on Job Satisfaction and Turnover Intention: A Study of Non-Supervisory Hotel Employees" International Journal of Hospitality Management, 31, 588-595.

Karatepe, O.M. ve Karadas, G. (2012) "The Effect of Management Commitment to Service Quality on Job Embeddedness and Performance Outcomes" Journal of Business Economics \& Management, 13(4); 614-636.

Karatepe, O.M. ve Ngeche, R.N. (2012) "Does Job Embeddedness Mediate the Effect of Work Engagement on Job Outcomes? A study of Hotel Employees in Cameroon" Journal of Hospitality Marketing \& Management, 21(4): 440-461.

Karatepe, O.M. ve Shahriari, S. (2014) "Job Embeddedness As A Moderator of The Impact of Organisational Justice on Turnover Intentions: A Study in Iran" International Journal of Tourism Research, 16, 22-32.

Kidd, J.M. ve Smewing, C. (2001) "The Role of The Supervisor In Career And Organizational Commitment" European Journal of Work and Organizational Psychology, 10 (1): 25-40.

Konovsky, M.A. ve Pugh, S.D. (1994) "Citizenship Behavior and Social Exchange" Academy of Management Journal, 37, 656-669.

Lambert, E. (2003) "Justice in Corrections: An Exploratory Study of the Impact of Organizational Justice on Correctional Staff" Journal of Criminal Justice, 31, 155-168.
Lambert, E.G., Hogan, N.L. ve Griffin, M.L. (2007) “The Impact of Distributive and Procedural Justice on Correctional Staff Job Stress, Job Satisfaction, And Organizational Commitment" Journal of Criminal Justice, 35, 644-656.

Lee, C.K., Song, H.J., Lee, H.M., Lee, S. ve Bernhard, B.J. (2013) "The Impact of CSR on Casino Employees' Organizational Trust, Job Satisfaction, and Customer Orientation: An Empirical Examination of Responsible Gambling Strategies" International Journal of Hospitality Management, 33, 406-415.

Martinussen, M., Richardsen, A.M. ve Burke, R.J. (2007) "Job Demands, Job Resources, And Burnout Among Police Officers" Journal of Criminal Justice, 35(3): 239249.

Mayer, R., Davis, J. ve Schoorman, D. (1995) "An Integrative Model of Organizational Trust" The Academy of Management Review, 20(3): 709-734.

Mayer, R.C. ve Gavin, M.B. (2005)“Trust in Management and Performance: Who Minds the Shop While the Employees Watch the Boss?" Academy of Management Journal, 48(5): 874- 888.

McAllister, D.J. (1995) "Affect and Cognition Based Trust as Foundations For Interpersonal Cooperation In Organizations" Academy of Management Journal, 38(1): 24-59.

Mishra, J. ve Morrissey, M. (1990) "Trust in Employee/ Employer Relationships: A Survey Of West Michigan Managers" Public Personnel Management, 19(4): 443485.

Mitchell, T.R., Holtom, B.C., Lee, T.W., Sablynski, C.J. ve Erez, M. (2001) "Why People Stay: Using Job Embeddedness to Predict Voluntary Turnover" Academy of Management Journal, 44, 1102-1121.

Niehoff, B.P. ve Moorman, R.H., (1993) "Justice as a Mediator of The Relationship between Methods of Monitoring and Organizational Citizenship Behaviour" Academy of Management Journal, 36(3): 527-556.

Renzl, B. (2008) "Trust in Management And Knowledge Sharing: The Mediating Effects Of Fear And Knowledge Documentation" Omega, 36, 206 220.

Robinson, R.N.S., Kralj, A., Solnet, D.J., Goh, E. ve Callan, V. (2014) "Thinking Job Embeddedness Not Turnover: Towards a Better Understanding of Frontline Hotel Worker Retention" International Journal of Hospitality Management, 36, 101- 109. 
Sekaran, U. (1992) Research Methods for Business - A Skill Building Approach, 2nd Edition, United States of America, John Wiley \& Sons, Inc.

Sekiguchi, T., Burton, J.P. ve Sablynski, C.J. (2008) "The Role of Job Embeddedness on Employee Performance: The Interactive Effects With LeaderMember Exchange And Organization-Based SelfEsteem" Personnel Psychology, 61, 761-792.

Şanlı, S.C. (2016) "Işgören Avukatlığı ve Algılanan Örgütsel Desteğin Çalışanların İşe Gömülmüşlük ve İşten Ayrılma Niyeti Üzerine Etkisi: Otel Çalışanları Üzerine Bir Araştırma" Yayınlanmamış Yüksek Lisans Tezi, MEÜ Sosyal Bilimler Enstitüsü.

Tanova, C. ve Holtom, B.C. (2008) "Using Job Embeddedness Factors to Explain Voluntary Turnover In Four European Countries" International Journal of Human Resource Management, 19(9): 1553-1568.

Tracey, J.B. ve Hinkin, T.R. (2008) "Contextual Factors and Cost Profiles Associated with Employee Turnover" Cornell Hospitality Quarterly, 49(1): 12-27.

Wang, H., Kenneth S.L., Rick D.H., Duanxu, W. ve Zhen X.C. (2005) "Leader-Member Exchange As A Mediator of The Relationship Between Transformational Leadership And Fellowes' Performance And
Organizational Citizenship Behaviour" Academy of Management Journal, 48(1): 420-432.

Webber, S.S. ve Klimoski, R.J. (2004) "Client-Project Manager Engagements, Trust And Loyalty" Journal of Organizational Behavior, 25. 997-1013.

Wong, Y.T., Ngo, H.Y. ve Wong, C.S. (2006) "Perceived Organizational Justice, Trust, And OCB: A Study of Chinese Workers In Joint Ventures And State-Owned Enterprises". Journal of World Business 41, 344-355.

Yang, J. T., (2010) Antecedents and Consequences of Job Satisfaction in The Hotel Industry" International Journal of Hospitality Management, 29(4): 609-619.

Yoon, M.H. ve Suh, J. (2003) “Organizational Citizenship Behaviors and Service Quality as External Effectiveness of Contact Employees" Journal of Business Research, 56(8): 597-611.

Zapata-Phelan, C.P., Colquitt, J.A., Scott, B.A. ve Livingston, B. (2009) "Procedural Justice, Interactional Justice, And Task Performance: The Mediating Role of Intrinsic Motivation' Organizational Behavior and Human Decision Processes. 108, 93-105.

Zopiatis, A., Constanti, P. ve Theocharous, A.L. (2014) "Job Involvement, Commitment, Satisfaction and Turnover: Evidence from Hotel Employees in Cyprus" Tourism Management, 41, 129-140. 